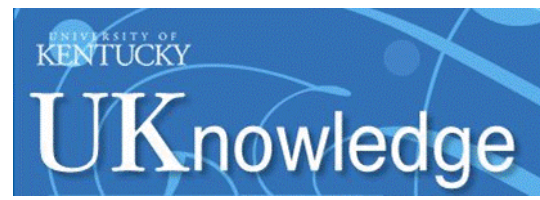

University of Kentucky

UKnowledge

\title{
Exploring Overlaps Between the Genomic and Environmental Determinants of LVH and Stroke: A Multicenter Study in West Africa
}

\author{
Abiodun M. Adeoye \\ University of Ibadan, Nigeria \\ Bruce Ovbiagele \\ Medical University of South Carolina \\ Philip Kolo \\ University of Ilorin Teaching Hospital, Nigeria \\ Lambert Appiah \\ Komfo Anokye Teaching Hospital, Ghana \\ Follow this and additional works at: https://uknowledge.uky.edu/epidemiology_facpub \\ 1'-inyemi Aje

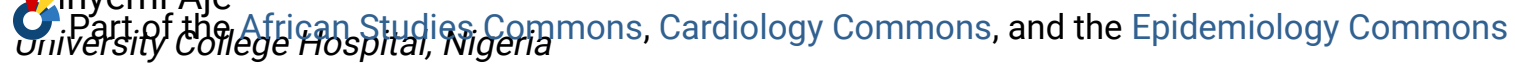 \\ Right click to open a feedback form in a new tab to let us know how this document benefits you.
}

\section{See next page for additional authors}

Repository Citation

Adeoye, Abiodun M.; Ovbiagele, Bruce; Kolo, Philip; Appiah, Lambert; Aje, Akinyemi; Adebayo, Oladimeji; Sarfo, Fred; Akinyemi, Joshua; Adekunle, Gregory; Agyekum, Francis; Shidali, Vincent; Ogah, Okechukwu; Lackland, Dan; Gebregziabher, Mulugeta; Arnett, Donna K.; Tiwari, Hemant K.; Akinyemi, Rufus; Olagoke, Ojo Olakanmi; Oguntade, Ayodipupo Sikiru; Olunuga, Taiwo; Uwanruochi, Kelechi; Jenkins, Carolyn; Adadey, Patrick; Iheonye, Henry; Owolabi, Lukman; Obiako, Reginald; Akinjopo, Samuel; Armstrong, Kevin; Akpalu, Albert; and Fakunle, Adekunle, "Exploring Overlaps Between the Genomic and Environmental Determinants of LVH and Stroke: A Multicenter Study in West Africa" (2017). Epidemiology and Environmental Health Faculty Publications. 45.

https://uknowledge.uky.edu/epidemiology_facpub/45

This Article is brought to you for free and open access by the Epidemiology and Environmental Health at UKnowledge. It has been accepted for inclusion in Epidemiology and Environmental Health Faculty Publications by an authorized administrator of UKnowledge. For more information, please contact UKnowledge@lsv.uky.edu. 


\title{
Exploring Overlaps Between the Genomic and Environmental Determinants of LVH and Stroke: A Multicenter Study in West Africa
}

\author{
Digital Object Identifier (DOI) \\ https://doi.org/10.1016/j.gheart.2017.01.001 \\ Notes/Citation Information \\ Published in Global Heart, v. 12, issue 2, p. 107-113.e5. \\ (C) 2017 World Heart Federation (Geneva). Published by Elsevier Ltd. All rights reserved.
}

This manuscript version is made available under the CC-BY-NC-ND 4.0 license

https://creativecommons.org/licenses/by-nc-nd/4.0/.

The document available for download is the authors' post-peer-review final draft of the article. Its title is "Exploring Overlaps between the Genomic and Environmental Determinants of Left Ventricular Hypertrophy and Stroke among Africans."

Due to the large number of authors, only the first 30 and the authors affiliated with the University of Kentucky are listed in the author section above. For the complete list of authors, please download this article or visit: https://doi.org/10.1016/j.gheart.2017.01.001

\section{Authors}

Abiodun M. Adeoye, Bruce Ovbiagele, Philip Kolo, Lambert Appiah, Akinyemi Aje, Oladimeji Adebayo, Fred Sarfo, Joshua Akinyemi, Gregory Adekunle, Francis Agyekum, Vincent Shidali, Okechukwu Ogah, Dan Lackland, Mulugeta Gebregziabher, Donna K. Arnett, Hemant K. Tiwari, Rufus Akinyemi, Ojo Olakanmi Olagoke, Ayodipupo Sikiru Oguntade, Taiwo Olunuga, Kelechi Uwanruochi, Carolyn Jenkins, Patrick Adadey, Henry Iheonye, Lukman Owolabi, Reginald Obiako, Samuel Akinjopo, Kevin Armstrong, Albert Akpalu, and Adekunle Fakunle 


\title{
Exploring Overlaps between the Genomic and Environmental Determinants of Left Ventricular Hypertrophy and Stroke among Africans
}

\section{A full list of authors and affiliations appears at the end of the article.}

\begin{abstract}
Background-Whether left ventricular hypertrophy $(\mathrm{LVH})$ is determined by similar genomic and environmental risk factors with stroke, or is simply an intermediate stroke marker, is unknown. We present a research plan and preliminary findings to explore the overlap in the genomic and environmental determinants of LVH and stroke among Africans participating in the Stroke Investigative Research and Education Network (SIREN) study.

Methods-SIREN is a transnational, multi-centre study involving acute stroke patients and age, ethnicity and sex-matched controls recruited from 9 sites in Ghana and Nigeria. Genomic and environmental risk factors and other relevant phenotypes for stroke and LVH are being collected and compared using standard techniques.
\end{abstract}

Results-This preliminary analysis included only 725 stroke patients (mean age 59.1 \pm 13.2 years; 54.3\% males). Fifty- five percent of the stroke subjects had LVH with greater proportion among women $(51.6 \%$ vs $48.4 \%, \mathrm{p}<0.001)$. Those with $\mathrm{LVH}$ were younger $(57.9 \pm 12.8$ vs $60.6 \pm 13.4 ; \mathrm{p}=0.006)$ and had higher mean systolic and diastolic BP $(167.1 / 99.5 \mathrm{mmHg}$ vs $151.7 / 90.6 \mathrm{mmHg}, \mathrm{p}<0.001$ ). Uncontrolled blood pressure (BP) at presentation was prevalent in subjects with LVH (76.2\% vs 57.7\%; p <0.001). Significant independent predictors of LVH were age, $<45$ years $(\mathrm{AOR}=1.91,95 \% \mathrm{CI}: 1.14$ to 3.19$)$, female gender $(\mathrm{AOR}=2.01 ; 95 \% \mathrm{CI}: 1.44$ to $2.81)$, and diastolic $\mathrm{BP}>90 \mathrm{mmHg}(\mathrm{AOR}=2.10 ; 95 \% \mathrm{CI}: 1.39$ to $3.19, \mathrm{p}<0.001)$.

Conclusion-The prevalence of LVH was high among stroke patients especially the younger ones suggesting a genetic component to LVH. Hypertension was a major modifiable risk factor for stroke as well as LVH. It is envisaged that the SIREN project will elucidate polygenic overlap (if present) between left ventricular hypertrophy and stroke among Africans, thereby defining the role of LVH as a putative intermediate cardiovascular phenotype and therapeutic target to inform interventions to reduce stroke risk in populations of African ancestry.

Corresponding Author: Mayowa O. Owolabi, MBBS, MSc, DM, FMCP, Department of Medicine, University College Hospital, Ibadan, Nigeria, West Africa., Phone: +234 802077 5595, mayowaowolabi@yahoo.com.

Publisher's Disclaimer: This is a PDF file of an unedited manuscript that has been accepted for publication. As a service to our customers we are providing this early version of the manuscript. The manuscript will undergo copyediting, typesetting, and review of the resulting proof before it is published in its final citable form. Please note that during the production process errors may be discovered which could affect the content, and all legal disclaimers that apply to the journal pertain. 


\section{INTRODUCTION}

Stroke is one of the leading causes of mortality and morbidity globally(1) and Africa has a significant burden with about $86 \%$ of all stroke deaths worldwide occurring in African and other low and middle income countries.(2) Cardiovascular disease (CVD), particularly hypertension, has become a significant source and contributor to the global disease burden. Of the 10 predominant modifiable risk factors accounting for $90 \%$ of stroke risk, hypertension is the strongest and most common.(3)

Hypertension is also a major determinant of left ventricular hypertrophy (LVH) which is a remodeling response to elevated blood pressure. Blacks have a higher prevalence of LVH compared to their Caucasian counterparts. $(4,5)$ The Dallas Heart Study, a population-based study, showed that LVH was 2- to 3-fold more common in black men and women versus white; such ethnic disparities are present in both normotensives and hypertensives. (4) Studies providing genomic explanation for these disparities are not conclusive. Pleiotropy is a phenomenon in which a genetic variation, usually a mutation in a single gene locus, affects multiple observable apparently non-related phenotypic traits may account for some of these overlaps and disparity.(6) Pleiotropic Genetic variation in NPY1R, NPY2R, NPY5R, CPE, IL15, and SFRP2, identified in hypertensive siblings, has been found to associate with LV phenotypes in blacks and/or whites.(7)

Electrocardiographic parameters such as Cornell product or QRS-complex product can be used to detect the presence of LVH. A number of genes associated with these two clinical parameters are also positively associated with cardiovascular diseases such as stroke has been identified. (8)

The diverse genomic variation of African population (9-11) provides a unique avenue for exploring novel genes and molecular independent or dependent pathways of stroke and LVH that could lead to better understanding of management options for stroke within the African and global populations.

There is an urgent need to accurately determine the current burden of LVH and stroke, and fully characterize and quantify the environmental and genetic factors underlying this epidemic in Africa. This is pertinent because an association between LVH and stroke has been reported (12), but the influence of genetics on this association is yet to be elucidated in the African environment (Figure 1). Currently, there are few genomic studies done involving African populations.(13) The Stroke Investigative Research Education and Network (SIREN) study seeks to address this knowledge gap. SIREN is strategically situated to explore a unique black African population to detect genetic determinants of LVH and stroke with the potential to identify novel genes and/or gene variants that predispose to alterations in left ventricular geometry and consequent stroke.

The understanding of the genomics of LVH and stroke among Africans would aid the preventive and interventional strategies in curtailing the burgeoning stroke epidemic in the region. We aim to identify, quantify, and compare the socio-demographic and clinical risk factors for stroke and LVH among Black Africans. 
We present preliminary findings and a research plan to explore if there are significant overlaps in the genomic and environmental determinants of LVH and stroke among Africans participating in the SIREN study.

\section{METHODS}

\section{Study design}

The study rationale and design has been described elsewhere.(14) The SIREN study is a multi-centre case-control study involving several sites in northern and southern Nigeria and northern and southern Ghana, which has been running since August 2014, with a targeted initial recruitment of 3000 cases and 3000 controls. Ethical approval was obtained from all study sites and informed consent was obtained from all subjects. Cases included consecutively recruited consenting adults (aged 18 years or older) with first clinical stroke within 8 days of current symptom onset or 'last seen without deficit' with cranial CT or MRI scan performed to confirm diagnosis within 10 days of symptom onset. We excluded those with stroke mimics, primary subarachnoid hemorrhage and previous strokes, which were not ascertained radiologically.

We collected basic demographic and lifestyle data including ethnicity and native language of the subjects and their parents, socioeconomic status, dietary patterns, routine physical activity, stress depression, cigarette smoking, and alcohol use as well as cardiovascular and anthropometric measurements using standard instruments. A detailed neurologic evaluation was conducted to assess neurologic deficits and determine stroke severity using the National Institute of Health Stroke Severity Score.(15) Stroke outcome was assessed using modifiedRankin Scale (mRS), at 1 month. Blood samples were collected from cases and controls at baseline for measurement of fasting lipid profile, blood glucose and HbA1c. Stroke diagnosis and phenotyping were based on clinical evaluation and brain neuroimaging (brain CT or MRI).

Hypertension was defined as sustained systolic $\mathrm{BP}>140 \mathrm{mmHg}$ or diastolic $\mathrm{BP}>90 \mathrm{mmHg}$ after onset of stroke, a history of hypertension, or taking antihypertensive medications before stroke. (14) Diabetes mellitus was defined based on previous history of diabetes mellitus, use of medications for diabetes mellitus, fasting glucose levels $>126 \mathrm{mg} / \mathrm{dl}$ and/or HBA1c > 6.5\% . (16) Dyslipidemia was defined in accordance with the recommendations of the US National Cholesterol Education Program as a high fasting serum total cholesterol $>=200 \mathrm{mg} / \mathrm{dl}$ or High Density lipoprotein $(\mathrm{HDL})<=40 \mathrm{mg} / \mathrm{dl}(17)$ or Low Density Lipoprotein (LDL) $>=130$ or Triglyceride(Trig) $\geq 150 \mathrm{mg} / \mathrm{dl}$ or history of use of statins before stroke. Smoking status was characterized as never, former, or current smoker. We defined current smokers as individuals who smoked any tobacco in the past 12 months and included those who had quit within the past year. Former smokers were defined as those who had quit more than a year earlier. Alcohol intake was categorized into never or former drinker, moderate drinker (1-30 drinks per month), drinker of more than 30 drinks per month, or binge drinker (>5 drinks per day at least once per month). $(3,18)$ Obesity was assessed using body-mass index and waist hip ratio. $(3,18)$ Individuals were classified as sedentary if they were not involved in exercise (including walking, cycling, or gardening) or strenuous exercise (jogging, football, and vigorous swimming) before the stroke. $(3,18)$ 


\section{Electrocardiography}

A standard (resting) 12-lead ECG was obtained in each subject by using a ECG acquisition box Model MGY-S3, Made in Germany and CONTEC ${ }^{\circledR}$ Workstation Model CONTEC EC8000G, Made in China at $25 \mathrm{~mm} / \mathrm{s}$ and $1 \mathrm{mV} / \mathrm{cm}$ calibration. Various parameters such as PR interval, QRS duration and axis, rate, rhythm, types of arrhythmia and QT intervals were measured. LVH was diagnosed using the following criteria: Sokolow-Lyon voltage (sum of the amplitudes of $\mathrm{S}$ wave in V1 and $\mathrm{R}$ wave in V5 or V6 $\geq 3.5 \mathrm{mV}$ ), sex-specific Cornell voltage (sum of the amplitudes of $\mathrm{S}$ wave in $\mathrm{V} 3$ and $\mathrm{R}$ wave in aVL2.0 $\mathrm{mV}$ in women and $2.8 \mathrm{mV}$ in men), and Cornell product [(RaVL $+\mathrm{SV} 3)+8 \mathrm{~mm}$ for women $] \times \mathrm{QRS}$ duration $\geq$ $2440 \mathrm{~mm}$. The preliminary results below were based on LVH criteria above.

\section{DNA extraction}

Thirty-five milliliters of whole blood was obtained using Vacutainer EDTA tubes, kept on ice and refrigerated at each peripheral study site. This is subsequently transferred to the Genomic Laboratory at Ibadan, Nigeria and the Molecular facilities at the Clinical Virology Laboratory, Department of Microbiology, University of Ghana Medical School Accra, Ghana and the Genomic Laboratory, Kumasi, Ghana for processing. Genomic DNA is extracted from whole blood with Gentra Systems PUREGENE DNA purification kit (Qiagen Group), and then checked for purity by determining the optical density with a nanodrop spectrophotometer which ensures that the DNA samples are of high purity with a 260/280 ratio 1.8-2.0 and 260/230 ratio >1.5. The PUREGENE kit allows between 5000-15,000ng DNA to be extracted from $300 \mu$ l of whole blood and also has a protocol to degrade any RNA present in elute. In order to avoid degradation of DNA, all DNA samples will be stored in aliquots at $-20^{\circ} \mathrm{C}$ in Ghana and shipped to Ibadan, Nigeria on dry ice for long term storage at $-80{ }^{\circ} \mathrm{C}$ in the Central SIREN Biobanking facilities. All subjects' biosamples are given unique barcode identifications.

\section{Genotyping and GWAS Protocol}

Genotyping will be performed using the versatile and unique H3Africa Genome Wide Linkage Analysis Study (GWAS) Array with over 700,000 African variants as well as diverse cardiometabolic and stroke related variants aiming to achieve $>80 \%$ coverage of SNPs with a minor allele frequency (MAF) $25 \%$ across the genome. We will also explore candidate SNPs to be selected from SNPs previously associated with stroke or LVH (Tables S1-S5). We will explore pathways within the frame work for the interaction among cardiovascular risk factors, cardiac diseases and stroke in Africa and beyond. (Figure 1)

The samples used for the customized candidate gene and GWAS analysis will achieve a chip wide call rate of $>98 \%$. SNPs will be excluded if the minor allele frequency (MAF) is $<0.01$ or fail the Hardy-Weinberg Equilibrium (HWE) test of $\mathrm{p}<1 \times 10^{-3}$. Also, sample or SNPs with missing rate greater than $10 \%$ will not be considered for further analysis. Population structure will be checked using the AWClust algorithm (19) and corrected in association analysis. Further, high inflation in QQ plot is also indicative of the evidence of structure.(20) 


\section{Sample size estimation and power justification}

We have $99.65 \%$ power to detect at least one causal SNP with Genetic Relative Risk (GRR) of 1.5 , with allele frequency as low as 0.04 for and $87.42 \%$ power to detect all 20 causal variants alpha level of 0.05 in GWAS setting with multiple test correction.

\section{Data management and statistical analysis}

All phenotype data collected from SIREN sites were transmitted to a secure data management and storage system at the Medical University of South Carolina. Neuroimaging data were processed using the SIREN ACCESS software (Patent Registration Number: NG/PT/NC/2016/2007).

For the current analysis of phenotype data, descriptive statistics, univariate analysis and logistic regression were performed at $\mathrm{p}<0.05$ to explore risk factors common to both stroke and LVH. For categorical variables, the Z-test for proportions was used to compare the risk factors between stroke survivors with and without LVH. Independent t-test was performed for continuous variables. Furthermore, among stroke survivors with LVH, similar analyses were conducted to investigate differences by to stroke type (Ischemic vs Hemorrhagic). In order to identify the independent predictors of $\mathrm{LVH}$, variables with $\mathrm{p}<0.1$ in the bivariate analyses were entered into a logistic regression model from which Odds Ratio (95\% CI) were estimated. Model fit was ascertained using the Hosmer-Lemeshow test.

Association analysis with genetic data will be performed using the PLINK software package.(21) Data files will be subsequently uploaded into a secure internet site to be accessed by study collaborators for analysis. Analysis tools provided in the MetaCore software suite developed by GeneGo (www.genego.com) will be used for pathway and network-based analysis (22) following identification of relevant pathways related to the neurobiology of LVH and stroke. The goal of the pathway and network-based analysis is to determine if SNP variants associated with LVH and stroke tend to cluster in biological pathways or networks that are of significance to stroke. The set-based method in PLINKv1.07 will be used to assess pathways of significance.(21)

\section{PRELIMINARY RESULTS (from ECG LVH and stroke risk factors)}

Of all the stroke subjects $(\mathrm{n}=725), 54.7 \%$ had $\mathrm{LVH}$ with greater proportion among women (51.6\% vs 48.4\%; $\mathrm{p}<0.001)$. (Table 1 ) Stroke subjects with LVH were younger (57.9 \pm 12.8 vs. $60.6 \pm 13.4 ; \mathrm{p}=0.006)$, had higher proportion of uncontrolled blood pressure at presentation ( $76.2 \%$ vs $57.7 \% ; \mathrm{p}<0.001)$, and a mean systolic and diastolic blood pressure(167.1/99.5 vs $151.7 / 90.6 \mathrm{mmHg}$; $\mathrm{p}<0.001$ ) (Tables 1 and 2).

Over one third of the participants were diabetic while $73.4 \%$ and $22.9 \%$ of them were dyslipidemic and obese respectively. The use of tobacco and heavy alcohol were not common. Patients with hemorrhagic stroke had a greater proportion of Sokolow Lyon LVH (52.8 vs $31.8 \%$; $\mathrm{p}<0.001$ ), while the Cornell product LVH prevalence were comparable. Patients with hemorrhagic stroke with $\mathrm{LVH}$ were younger ( $53.0 \pm 11.5$ vs $59.9 \pm 13.2 \mathrm{yrs}$.) with higher SBP and DBP $(177.3 / 107.3 \mathrm{mmHg}$ vs $160.7 / 95.4 \mathrm{mmHg}$; $\mathrm{p}<0.001)$, while a 
greater proportion of ischemic stroke were diabetic ( $44.8 \%$ vs $29.3 \%$; $\mathrm{p}=0.008)$ and had prior cardiac disease ( $18.8 \%$ vs $10.3 \% ; \mathrm{p}=0.05)$.(Table 2$)$.

Significant independent predictors of $\mathrm{LVH}$ found were age $<45$ years $(\mathrm{AOR}=1.91,95 \% \mathrm{CI}$ : 1.14 to 3.19$), \mathrm{p}=0.014)$, female gender ( $\mathrm{AOR}=2.01 ; 95 \% \mathrm{CI}: 1.44$ to $2.81, \mathrm{p}<0.001$ ) and diastolic blood pressure $>90 \mathrm{mmHg}(\mathrm{AOR}=2.10 ; 95 \% \mathrm{CI}: 1.39$ to $3.19, \mathrm{p}<0.001)$ as shown in Table 3.

\section{DISCUSSION}

In this current study, more than half of the stroke patients had LVH with female preponderance. Hypertension was the major modifiable risk factor for both stroke and LVH. Depending on the study design and location, the prevalence of LVH in hypertensive patients ranges from 36\%-41\%.(23) Our findings of LVH of 55\% was higher than earlier studies which reported $38 \%(24,25)$ and $40 \%(24)$ in US black populated community and Japanese population respectively. This was lower than $80 \%$ in Houston cocaine users cohort.(26) The inconsistency in the prevalence underscores the influence of genomics and environment on LVH and stroke; persons with African ancestry are more prone to LVH and stroke.(27)

An interesting finding in the study is the female preponderance which is contrary to the male predominance in a previous study.(28) In that same study, however, LVH by Cornell voltageduration product criteria was predominantly associated with female gender, whereas presence of ECG LVH by Sokolow-Lyon voltage criteria was predominantly related to male gender, and black race. The gender disparity was therefore inconclusive. Some other studies have reported the gender disparity in cardiovascular morbidity and mortality.(29, 30) Similar to our finding, female blacks have been reported to have more LVH than Caucasians. (31, 32)

In our study, greater than a third of the participants were diabetic while $73.4 \%$ and $22.9 \%$ of them were dyslipidemic and obese respectively. Diabetes was not significantly correlated with presence of LVH but it was significantly associated with ischaemic stroke. This was the same finding in INTERSTROKE (16) and EUROSTROKE(36). Case-control studies of stroke patients and prospective epidemiological studies in other diverse populations have also confirmed an independent effect of diabetes with a relative risk of ischemic stroke in persons with diabetes from 1.8 to 3 . (5) This has been attributed to increased susceptibility to atherosclerosis and increased prevalence of atherogenic risk factors such as hypertension, obesity, and abnormal blood lipids in diabetics.

In our study dyslipidemia was not significantly associated with LVH, nor was it associated with ischaemic stroke just as it was reported in EUROSTROKE(36). A direct link between hypercholesterolemia and ischemic stroke has not been established, despite a confirmed positive relationship with carotid atherosclerosis. The established benefit of statins have also been in prevention of secondary strokes, not primary events as in our study. (5)

Current smoking was not significantly associated with LVH or stroke type in our study. The number of smokers was however very small, $2.5 \%$, and this could explain the non- 
significance. In EUROSTROKE(36), for instance, smokers comprised of $41.4-41.9 \%$ of stroke cases.

Presence of LVH in stroke has been shown to increase the risk of repeat stroke and other cardiovascular events. $(33,34)$ While certain hypotheses have been given to explain why LVH predisposes for coronary heart disease and death(35), the mechanisms for stroke have not been conclusive.

\section{Strengths and limitations}

This is the largest exploration of the interactions among vascular risk factors, LVH and stroke among Africans to date. The preliminary findings support the exploration of genomic investigation into the contribution and relationship of LVH and stroke among African Blacks. It also provides a unique opportunity to identify genes associated with $\mathrm{LVH}$, stroke or both. This would also serve as a chance to compare the genetic constitution of West African blacks in respect with LVH and stroke with other racial databases.

Finally, this study would enhance the multi-dimensional strategy for combating the burgeoning epidemic of stroke in Sub-Saharan Africa.

Some potential challenges include those associated with equipment due to poor health care infrastructure and frequent power outages. Efforts have been made to ensure all centres collaborating in this study have at least a CT scan or MRI machine, ECG machine, and echocardiography machine with a trans-thoracic transducer. To address power outages, alternative would be utilized while for the equipment breakdown, the sites utilize private facilities which are readily available and nearby. Solar powered freezers are also available to keep blood samples in all the collaborating centres.

Controls were not included in this preliminary analysis which limit our ability to infer the association between LVH and stroke. Echocardiography findings were also not included in this analysis. More detailed analysis will be performed after recruitment of the initial 3000 case control pairs.

\section{CONCLUSION}

LVH affects over half of the African patients with stroke, especially females. The preponderance of LVH in the younger patients with stroke suggests genetic underpinnings which we plan to unravel within the SIREN study. Cardiovascular risk factors especially hypertension may serve as intermediate phenotypes for both LVH and stroke. Understanding these interactions could provide multiple targets for reducing the increasing stroke among individuals of African ancestry.

\section{Supplementary Material}

Refer to Web version on PubMed Central for supplementary material. 


\section{Authors}

Abiodun Adeoye, MD ${ }^{1}$, Bruce Ovbiagele, $\mathrm{MD}^{2}$, Philip Kolo, $\mathrm{MD}^{3}$, Lambert Appiah, $\mathrm{MD}^{4}$, Akinyemi Aje, $\mathrm{MD}^{5}$, Oladimeji Adebayo, $\mathrm{MD}^{5}$, Fred Sarfo, $\mathrm{MD}, \mathrm{PhD}^{4}$, Joshua Akinyemi, $\mathrm{PhD}^{1}$, Gregory Adekunle, $\mathrm{MPH}^{1}$, Francis Agyekum, $\mathrm{MD}^{6}$, Vincent Shidali, $\mathrm{MD}^{7}$, Okechukwu Ogah, $\mathrm{MD}^{1}$, Dan Lackland, $\mathrm{PhD}^{2}$, Mulugeta Gebregziabher, $\mathrm{PhD}^{2}$, Donna Arnett, $\mathrm{PhD}^{15}$, Hemant K. Tiwari, $\mathrm{PhD}^{8}$, Rufus Akinyemi, MD, PhD ${ }^{9}$, Ojo Olakanmi Olagoke, $\mathrm{MD}^{5}$, Ayodipupo Sikiru Oguntade, $\mathrm{MD}^{5}$, Taiwo Olunuga, $\mathrm{MD}^{9}$, Kelechi Uwanruochi, MD ${ }^{13}$, Carolyn Jenkins, $\mathrm{PhD}^{2}$, Patrick Adadey, MD ${ }^{6}$, Henry Iheonye, $\mathrm{MD}^{7}$, Lukman Owolabi, MD ${ }^{10}$, Reginald Obiako, $\mathrm{MD}^{7}$, Samuel Akinjopo, MB.BS ${ }^{5}$, Kevin Armstrong, BSc ${ }^{2}$, Albert Akpalu, $\mathrm{MD}^{6}$, Adekunle Fakunle, $\mathrm{MPH}^{1}$, Raelle Saulson, MPH${ }^{2}$, Mayowa Aridegbe, $\mathrm{BSc}^{19}$, Paul Olowoyo, MD ${ }^{16}$, Godwin Osaigbovo, $\mathrm{MD}^{14}$, Josephine Akpalu, $\mathrm{MD}^{6}$, Bimbo Fawale, $\mathrm{MD}^{11}$, Philip Adebayo, $\mathrm{MD}^{12}$, Oyedunni Arulogun, $\mathrm{PhD}^{1}$, Philip Ibinaiye, $\mathrm{MD}^{7}$, Atinuke Agunloye, $M D^{1}$, Naser Ishaq, $\mathrm{MD}^{10}$, Kolawole Wahab, $\mathrm{MD}^{3}$, Onoja Akpa, $\mathrm{PhD}^{1}$, Omisore Adeleye, $\mathrm{MD}^{11}$, Andrew Bock-Oruma, MD ${ }^{17}$, Godwin Ogbole, MD ${ }^{1}$, Sylvia Melikam, $M \mathrm{MS}^{1}$, Joseph Yaria, MD ${ }^{5}$, Luqman Ogunjimi, MD ${ }^{5}$, Abdul Salaam, MD ${ }^{14}$, Taofiki Sunmonu, MD ${ }^{18}$, Akintomiwa Makanjuola, $\mathrm{MD}^{5}$, Temitope Farombi, MD ${ }^{5}$, Ruth Laryea, $\mathrm{BSc}^{6}$, Ezinne Uvere, $\mathrm{MPH}^{1}$, Salaam Kehinde, $\mathrm{MSc}^{1}$, Innocent Chukwuonye, $M D^{13}$, Paschal Azuh, $\mathrm{MD}^{7}$, Morenikeji Komolafe, $\mathrm{MD}^{11}$, Adeseye Akintunde, $\mathrm{MD}^{12}$, Olugbo Obiabo, MD ${ }^{17}$, Olusegun Areo, MD ${ }^{16}$, Issa Kehinde, B.Sc ${ }^{1}$, Adeniyi G.

Amusa, MD ${ }^{14}$, and Mayowa Owolabi, MD, Dr.M ${ }^{1}$ on behalf of SIREN Team as part of H3Africa Consortium

\section{Affiliations}

${ }^{1}$ University of Ibadan, Ibadan, Nigeria

${ }^{2}$ Medical University of South Carolina, South Carolina, USA

${ }^{3}$ University of Ilorin Teaching Hospital, Nigeria

${ }^{4}$ Komfo Anokye Teaching Hospital, Kumasi, Ghana

5University College Hospital, Ibadan

${ }^{6}$ University of Ghana Medical School, Accra, Ghana

${ }^{7}$ Ahmadu Bello University, Zaria, Nigeria

${ }^{8}$ University of Alabama at Birmingham, Birmingham, USA

${ }^{9}$ Federal Medical Centre, Abeokuta, Nigeria

${ }^{10}$ Aminu Kano Teaching Hospital, Nigeria

${ }^{11}$ Obafemi Awolowo University Teaching Hospital, Ile-Ife, Nigeria

${ }^{12}$ Ladoke Akintola University of Technology, Ogbomoso, Nigeria

${ }^{13}$ Federal Medical Center, Umuahia, Abia State

${ }^{14}$ Jos University Teaching Hospital Jos, Nigeria 


\author{
15University of Kentucky \\ ${ }^{16}$ Federal University Teaching Hospital, Ido-Ekiti, Nigeria \\ ${ }^{17}$ Delta State University Teaching Hospital, Ogara, Nigeria \\ ${ }^{18}$ Federal Medical Centre, Owo, Nigeria \\ ${ }^{19}$ Sacred Heart Hospital, Abeokuta, Nigeria
}

\title{
Acknowledgments
}

\section{Funding}

This work is supported by the National Institutes of Health (NIH) and National Institute of Neurological Disorders and Stroke (NINDS) (Grant 1U54HG007479)

\section{References}

1. Feigin VL, Forouzanfar MH, Krishnamurthi R, Mensah GA, Connor M, Bennett DA, et al. Global and regional burden of stroke during 1990-2010: findings from the Global Burden of Disease Study 2010. The Lancet. 2014; 383(9913):245-55.

2. Feigin VL. Stroke epidemiology in the developing world. The Lancet. 2005; 365(9478):2160-1.

3. O’Donnell MJ, Xavier D, Liu L, Zhang H, Chin SL, Rao-Melacini P, et al. Risk factors for ischaemic and intracerebral haemorrhagic stroke in 22 countries (the INTERSTROKE study): a case-control study. The Lancet. 2010; 376(9735):112-23.

4. Drazner MH, Dries DL, Peshock RM, Cooper RS, Klassen C, Kazi F, et al. Left Ventricular Hypertrophy Is More Prevalent in Blacks Than Whites in the General Population The Dallas Heart Study. Hypertension. 2005; 46(1):124-9. [PubMed: 15939807]

5. Koren MJ, Mensah GA, Blake J, Laragh JH, Devereux RB. Comparison of left ventricular mass and geometry in black and white patients with essential hypertension. American journal of hypertension. 1993; 6(10):815-23. [PubMed: 8267936]

6. Stearns FW. One hundred years of pleiotropy: a retrospective. Genetics. 2010; 186(3):767-73. [PubMed: 21062962]

7. Arnett DK, Devereux RB, Rao DC, Li N, Tang W, Kraemer R, et al. NOVEL GENETIC VARIANTS CONTRIBUTING TO LEFT VENTRICULAR HYPERTROPHY: THE HYPERGEN STUDY: Genetic variants for LV hypertrophy. Journal of hypertension. 2009; 27(8):1585. [PubMed: 19593212]

8. Ishikawa J, Ishikawa S, Kabutoya T, Gotoh T, Kayaba K, Schwartz JE, et al. Cornell product left ventricular hypertrophy in electrocardiogram and the risk of stroke in a general population. Hypertension. 2009; 53(1):28-34. [PubMed: 19015402]

9. Tishkoff SA, Reed FA, Friedlaender FR, Ehret C, Ranciaro A, Froment A, et al. The genetic structure and history of Africans and African Americans. Science. 2009; 324(5930):1035-44. [PubMed: 19407144]

10. Adeyemo AA, Chen G, Chen Y, Rotimi C. Genetic structure in four West African population groups. BMC genetics. 2005; 6(1):1. [PubMed: 15634360]

11. Patin E, Laval G, Barreiro LB, Salas A, Semino O, Santachiara-Benerecetti S, et al. Inferring the demographic history of African farmers and Pygmy hunter-gatherers using a multilocus resequencing data set. PLoS Genet. 2009; 5(4):e1000448. [PubMed: 19360089]

12. Bots ML, Nikitin Y, Salonen JT, Elwood PC, Malyutina S, Freire de Concalves A, et al. Left ventricular hypertrophy and risk of fatal and non-fatal stroke. EUROSTROKE: a collaborative study among research centres in Europe. Journal of epidemiology and community health. 2002; 56(Suppl 1):i8-13. [PubMed: 11815638]

13. De Vries J, Pepper M. Genomic sovereignty and the African promise: mining the African genome for the benefit of Africa. Journal of Medical Ethics. 2012 medethics-2011-100448. 
14. Akpalu A, Sarfo FS, Ovbiagele B, Akinyemi R, Gebregziabher M, Obiako R, et al. Phenotyping stroke in sub-Saharan Africa: stroke investigative research and education network (SIREN) phenomics protocol. Neuroepidemiology. 2015; 45(2):73-82. [PubMed: 26304844]

15. Lyden PD, Lu M, Levine SR, Brott TG, Broderick J, Group NrSS. A modified national institutes of health stroke scale for use in stroke clinical trials preliminary reliability and validity. Stroke; a journal of cerebral circulation. 2001; 32(6):1310-7.

16. Organization WH. Use of glycated haemoglobin (HbA1c) in diagnosis of diabetes mellitus: abbreviated report of a WHO consultation. 2011

17. Lorenzo C, Williams K, Hunt KJ, Haffner SM. The National Cholesterol Education ProgramAdult Treatment Panel III, International Diabetes Federation, and World Health Organization definitions of the metabolic syndrome as predictors of incident cardiovascular disease and diabetes. Diabetes care. 2007; 30(1):8-13. [PubMed: 17192325]

18. O’Donnell M, Xavier D, Diener C, Sacco R, Lisheng L, Zhang H, et al. Rationale and design of INTERSTROKE: a global case-control study of risk factors for stroke. Neuroepidemiology. 2010; 35(1):36-44. [PubMed: 20389123]

19. Gao X, Starmer JD. AWclust: point-and-click software for non-parametric population structure analysis. BMC bioinformatics. 2008; 9(1):1. [PubMed: 18173834]

20. Price AL, Patterson NJ, Plenge RM, Weinblatt ME, Shadick NA, Reich D. Principal components analysis corrects for stratification in genome-wide association studies. Nature genetics. 2006; 38(8):904-9. [PubMed: 16862161]

21. Purcell S, Neale B, Todd-Brown K, Thomas L, Ferreira MA, Bender D, et al. PLINK: a tool set for whole-genome association and population-based linkage analyses. The American Journal of Human Genetics. 2007; 81(3):559-75. [PubMed: 17701901]

22. Torkamani A, Topol EJ, Schork NJ. Pathway analysis of seven common diseases assessed by genome-wide association. Genomics. 2008; 92(5):265-72. [PubMed: 18722519]

23. Cuspidi C, Sala C, Negri F, Mancia G, Morganti A. Prevalence of left-ventricular hypertrophy in hypertension: an updated review of echocardiographic studies. Journal of human hypertension. 2012; 26(6):343-9. [PubMed: 22113443]

24. Yamazaki T, Yanaka K, Aoki T, Matsuki T, Ono F, Fukuda T, et al. Cardiac function estimated by Doppler echocardiography in patients with hypertensive intracerebral hemorrhage. No to shinkei= Brain and nerve. 2000; 52(6):501-5. [PubMed: 10875121]

25. Albright KC, Burak JM, Chang TR, Aysenne A, Siegler JE, Schluter L, et al. The Impact of Left Ventricular Hypertrophy and Diastolic Dysfunction on Outcome in Intracerebral Hemorrhage Patients. ISRN stroke. 2013; 2013

26. Martin-Schild S, Albright KC, Hallevi H, Barreto AD, Philip M, Misra V, et al. Intracerebral hemorrhage in cocaine users. Stroke; a journal of cerebral circulation. 2010; 41(4):680-4.

27. Lee DK, Marantz PR, Devereux RB, Kligfield P, Alderman MH. Left ventricular hypertrophy in black and white hypertensives: standard electrocardiographic criteria overestimate racial differences in prevalence. Jama. 1992; 267(24):3294-9. [PubMed: 1534587]

28. Okin PM, Devereux RB, Jern S, Kjeldsen SE, Julius S, Dahlöf B, et al. Baseline characteristics in relation to electrocardiographic left ventricular hypertrophy in hypertensive patients The Losartan Intervention For Endpoint Reduction (LIFE) in hypertension study. Hypertension. 2000; 36(5): 766-73. [PubMed: 11082141]

29. Adeoye AM, Adewoye IA, Dairo DM, Adebiyi A, Lackland DT, Ogedegbe G, et al. Excess Metabolic Syndrome Risks Among Women Health Workers Compared With Men. The Journal of Clinical Hypertension. 2015; 17(11):880-4. [PubMed: 26053898]

30. Adeoye AM, Adebiyi A, Owolabi MO, Lackland DT, Ogedegbe G, Tayo BO. Sex Disparity in Blood Pressure Levels Among Nigerian Health Workers. The Journal of Clinical Hypertension. 2015

31. de Simone G, Devereux RB, Roman MJ, Alderman MH, Laragh JH. Relation of obesity and gender to left ventricular hypertrophy in normotensive and hypertensive adults. Hypertension. 1994; 23(5):600-6. [PubMed: 8175168] 
32. East MA, Jollis JG, Nelson CL, Marks D, Peterson ED. The influence of left ventricular hypertrophyon survival in patients with coronaryartery disease: do race and gender matter? Journal of the American College of Cardiology. 2003; 41(6):949-54. [PubMed: 12651039]

33. Pop GA, Koudstaal PJ, Meeder HJ, Algra A, van Latum JC, van Gijn J. Predictive value of clinical history and electrocardiogram in patients with transient ischemic attack or minor ischemic stroke for subsequent cardiac and cerebral ischemic events. Archives of neurology. 1994; 51(4):333-41. [PubMed: 8155010]

34. Bots M, Nikitin Y, Salonen J, Elwood PC, Malyutina S, de Concalves AF, et al. Left ventricular hypertrophy and risk of fatal and non-fatal stroke. EUROSTROKE: a collaborative study among research centres in Europe. Journal of epidemiology and community health. 2002; 56(suppl 1):i8i13. [PubMed: 11815638]

35. Levy D, Salomon M, D’Agostino RB, Belanger AJ, Kannel WB. Prognostic implications of baseline electrocardiographic features and their serial changes in subjects with left ventricular hypertrophy. Circulation. 1994; 90(4):1786-93. [PubMed: 7923663] 


\section{Highlights}

- $\quad$ Left ventricular hypertrophy(LVH) was found in more than half of African stroke patients.

- $\quad$ LVH was more common in the younger ones suggesting a genetic component.

- $\quad$ Hypertension was a major modifiable risk factor for stroke as well as LVH

- $\quad$ SIREN will elucidate polygenic overlap between LVH and stroke among Africans. 
Genetic/Genomic risk factors (SNPs, CNVs, InDels, Transcriptome)

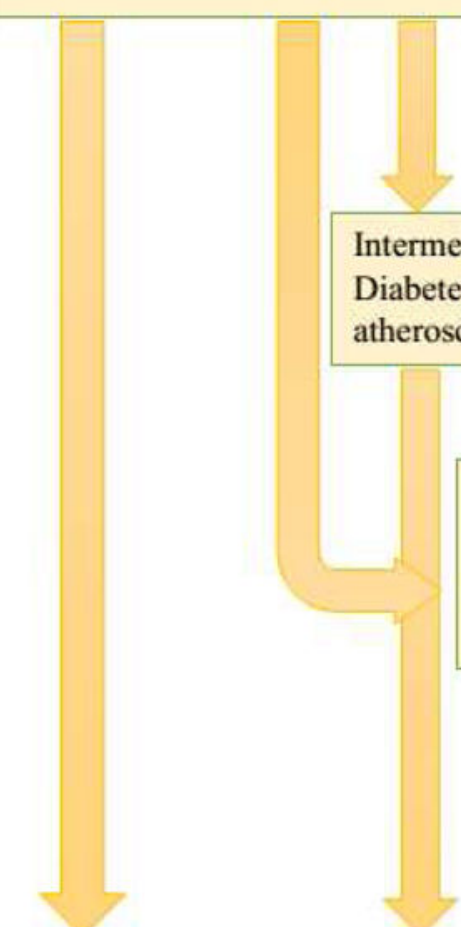

Environmental risk factors eg alcohol, smoking, diet, sedentary lifestyle, Postinfectious Rheumatic Heart Disease

Stroke (Ischemic and hemorrhagic) occurrence, type, subtype and outcome

Figure 1.

Framework for the interaction among cardiovascular risk factors, cardiac diseases, and stroke in Africa and beyond. 
Adeoye et al.

Page 15

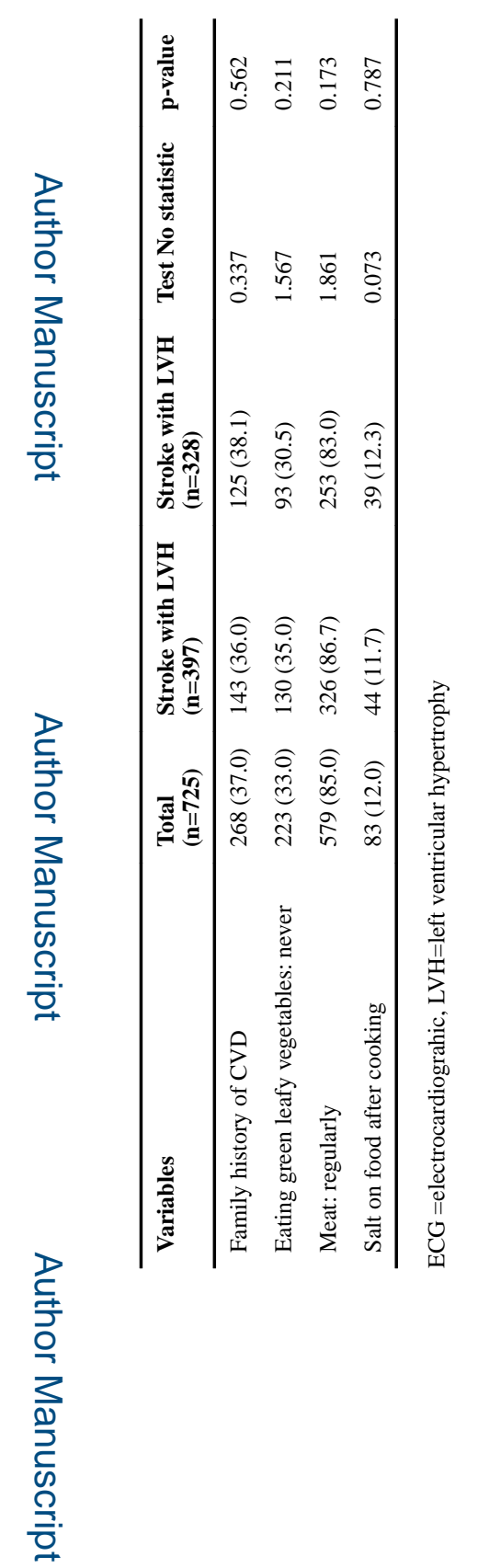

로을

Glob Heart. Author manuscript; available in PMC 2018 June 01. 


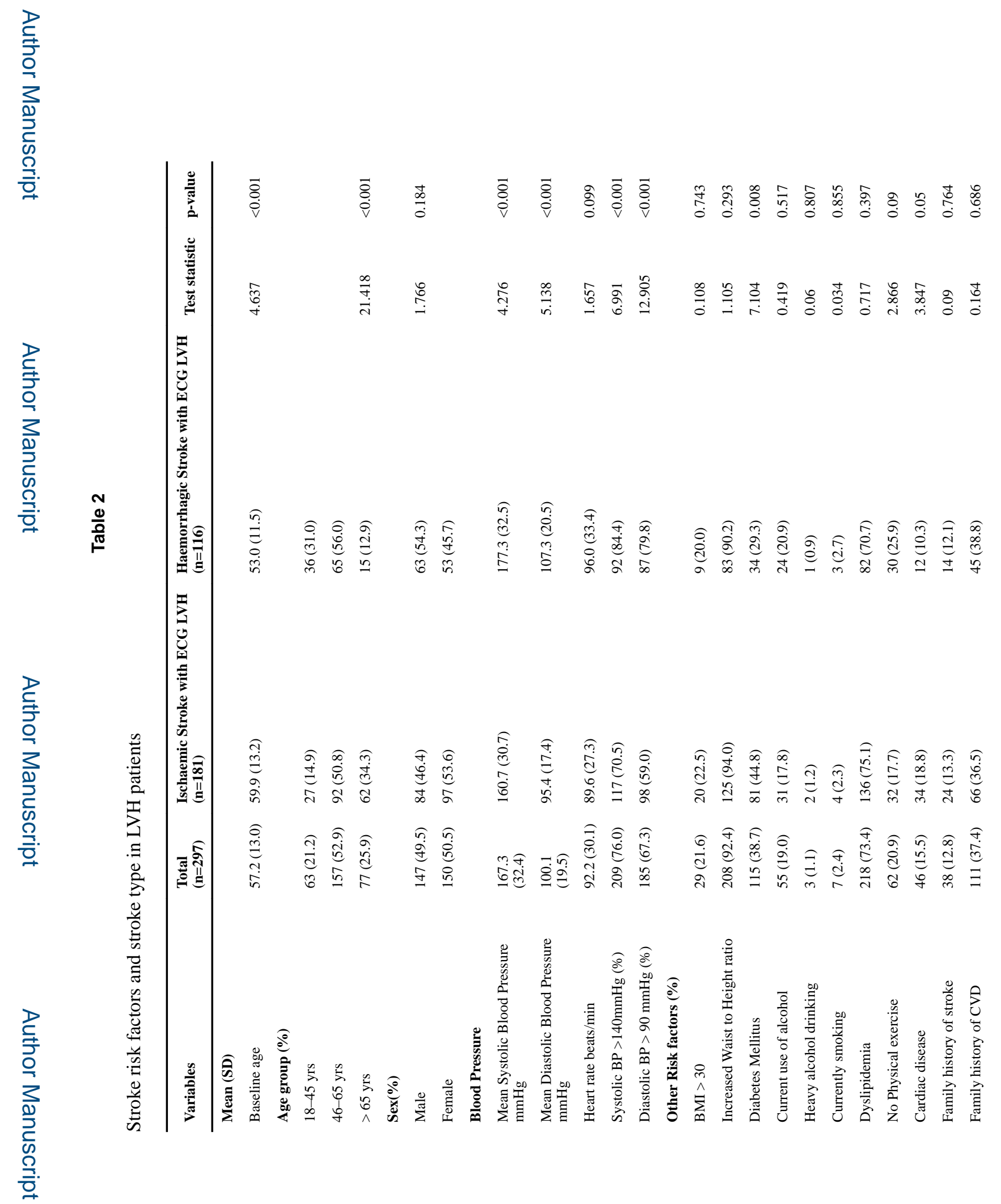

Glob Heart. Author manuscript; available in PMC 2018 June 01. 
Adeoye et al.

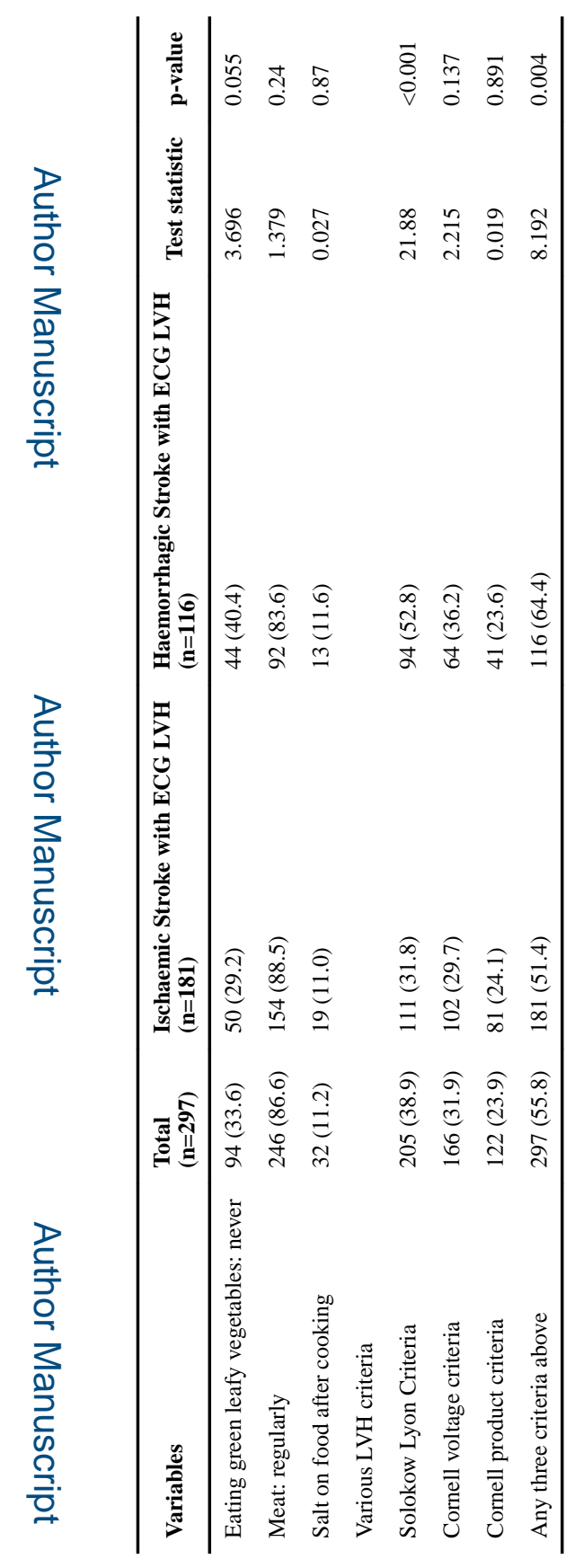

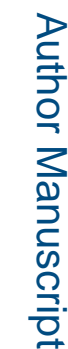

Glob Heart. Author manuscript; available in PMC 2018 June 01. 


\section{Table 3}

Independent predictors of LVH among stroke patients

\begin{tabular}{lll}
\hline Variables & AOR $(\mathbf{9 5 \%}$ CI) & p-value \\
\hline Baseline Age group (years) & & \\
$18-45$ & $1.91(1.14-3.19)$ & $\mathbf{0 . 0 1 4}$ \\
$46-65$ & $1.35(0.93-1.95)$ & 0.116 \\
$>65$ & 1.00 & \\
Female gender & $2.01(1.44-2.81)$ & $<\mathbf{0 . 0 0 1}$ \\
Average SBP >140 & $1.08(0.62-1.87)$ & 0.788 \\
Average DBP $>90$ & $2.10(1.39-3.19)$ & $<\mathbf{0 . 0 0 1}$ \\
Hypertension & $1.73(0.71-4.24)$ & 0.228 \\
Mean Arterial Blood Pressure & $1.01(0.99-1.02)$ & 0.061 \\
\hline
\end{tabular}

